\title{
Flipped classroom em História e Geografia de Portugal: contributos de um estudo numa turma do $5^{\circ}$ ano
}

Flipped classroom in History and Geography

of Portugal: a study in 5th grade class

Cláudia Rolo*

Pedro Teixeira Pereira**

\section{Resumo}

O artigo apresenta uma experiência inovadora de ensino da disciplina História e Geografia de Portugal com 22 alunos de uma turma do $5^{\circ}$ ano de escolaridade. Durante a Prática de Ensino Supervisionada de aulas dessa disciplina, própria do Mestrado em "Ensino do $1^{\circ}$ e $2^{\circ}$ Ciclos do Ensino Básico", propôs-se a inversão da prática docente com uso da flipped classroom. Os resultados sugerem que a flipped classroom permitiu não só o aprofundamento dos conteúdos, mas também o desenvolvimento de competências subjacentes ao raciocínio, às formas e ferramentas de trabalho e à componente social, despertando nos alunos o gosto pela História e Geografia de Portugal.

Palavras-chave: flipped classroom; História e Geografia de Portugal; ensino e aprendizagem.

\begin{abstract}
This paper presents an innovative experience teaching the discipline History and Geography of Portugal with 22 class of students of the 5th year. During Supervised Teaching Practice lessons of this discipline that is related to the Master in "Teaching 1st and 2nd cycles of Basic Education", we proposed a change in the teaching practice through the flipped classroom. The results suggest that the flipped classroom allowed not only the deepening of the contents, but also the development of skills underlying logic, forms and tools of work and social components, making students like History and Geography of Portugal. Keywords: Flipped classroom; History and geography of Portugal; Teaching and Learning.
\end{abstract}

\footnotetext{
* Mestre em Ensino do $1^{\circ}$ e $2^{\circ}$ Ciclos do Ensino Básico. Escola Superior de Educação do Instituto Politécnico de Viana do Castelo. Viana do Castelo, Portugal. claudiarolo@ipvc.pt

** Doutor em História Comparada Política e Social. Escola Superior de Educação do Instituto Politécnico de Viana do Castelo. Viana do Castelo, Portugal. pereirapedro@ese.ipvc.pt
} 
A Assessment and Teaching of 21st Century skills agrupou, sob o acrónimo KSAVE: knowledge, skills, attitudes, values and ethics, dez competências pretendendo a formação dos alunos para um mercado de trabalho em acelerada mutação onde a informação é um bem de livre acesso. Incluem-se 1) a criatividade e a inovação; o pensamento crítico, a resolução de problemas, a tomada de decisões; a capacidade de aprender a aprender e a metacognição nas competências de raciocínio; 2) a comunicação, a colaboração nas formas de trabalhar; 3) a literacia informativa e a literacia em TIC nas ferramentas de trabalho; e 4) a cidadania; a vida e a carreira; a iniciativa e empreendedorismo e a responsabilidade pessoal e social nas competências sociais (Binkley et al., 2012). No mesmo sentido também a Organização para a Cooperação e Desenvolvimento Económico (OCDE, 2015, p.33) defende que:

Education and skills are central to employability. Young people who leave school before they achieve a sufficient level of proficiency in literacy and numeracy find it difficult to enter the labour market. Increasingly, employers are looking for workers who are not proficient in these cognitive skills, but can also apply those skills to solve problems, and who are also deft in "soft" skills, such as communicating at working.

Ora, os alunos que encontrámos na sala de aula do $2^{\circ}$ Ciclo do Ensino Básico nasceram com a massificação do uso do computador e da internet. Enquanto realizam o seu trabalho de casa estão, por vezes, a enviar SMS para os seus colegas ou a ouvir música online. Nos seus bolsos transportam smartphones com uma maior capacidade de processamento do que os computadores que levaram os astronautas pela primeira vez à Lua. Apenas uma ínfima parte dessas potencialidades é absorvida pela sala de aula. A projeção de transparências cedeu o seu lugar às apresentações de slides animados. Substituiu-se o quadro de lousa preta pelo quadro branco ou pelo quadro interativo, o giz pelo marcador. Os televisores deram lugar aos computadores e as cassetes VHS aos recursos produzidos pelos grupos editoriais.

Pelo exposto, tornam-se pertinentes as seguintes questões: Estarão os alunos de uma turma do $5^{\circ}$ ano de uma escola pública, situada numa zona rural do norte de Portugal, preparados para responder às exigências do século XXI? Qual o contributo do ensino e aprendizagem da História e Geografia de Portugal no desenvolvimento dessas competências? 
Espelhando a realidade da sua povoação - baixa frequência do ensino secundário e superior -, 11 participantes no estudo desejavam findar o seu percurso académico com o término do ensino secundário; três pretendiam aceder ao ensino superior e os restantes não anteviram o seu percurso académico.

Durante a fase da observação das atitudes dos alunos perante a disciplina de História e Geografia de Portugal, verificou-se, de modo generalizado, uma estratificação da turma em dois grupos minoritários: alunos extremamente participativos, empenhados em alcançar bons resultados, e alunos que não se sentiam motivados a intervir, com baixa autoestima e bastante morosos na realização das atividades; e um grupo maioritário de alunos que só respondiam quando solicitados, satisfazendo passivamente os propósitos. Além disso, verificava-se uma estandardização dos comportamentos intragrupo.

Os alunos focavam-se excessivamente nos resultados e não em seu processo de aprendizagem que era demasiado rotineiro; por outras palavras, na sala de aula, os alunos estavam envolvidos nos níveis mais baixos da Taxonomia Revista de Bloom: lembrar e entender e, esporadicamente, aplicar. Os níveis superiores dessa Taxonomia - avaliar e criar - só poderiam ser alcançados fora da sala de aula, sem o feedback do professor. Segundo Bergmann e Sams (2012), essa metodologia provoca um desvio: o aluno que não compreendeu todos os assuntos durante a primeira exposição estará, à partida, mais inseguro e com menores expectativas, revelando sérias dificuldades em apropriar-se dos conteúdos da segunda aula, conduzindo ao insucesso a longo prazo.

"Estuda-se História para compreender o mundo em que vivemos e para poder actuar nele com espírito crítico e não simplesmente para recordar factos heroicos ou personagens do antigamente" (Félix et al., 1996, p.18). Melo (2004, p.88) defende que ao paradigma construtivista de ensino e aprendizagem subjaz que o ensino da História deve: 1) "promover competências que possibilitem ... lidar com as características das fontes históricas, e a validade e a relevância da sua informação" e com o uso de "procedimentos descritivos e explicativos, necessários à compreensão e interpretação dos acontecimentos históricos particulares"; 2) "considerar como relevantes o conhecimento tácito dos alunos, os conhecimentos históricos e de outros saberes disciplinares previamente adquiridos"; assim como, 3) "privilegiar o envolvimento dos alunos na construção do conhecimento histórico". Como tal, a História tem uma clara responsabilidade de formar os indivíduos para a sensibilidade social e ética e para 
a resposta à progressiva mobilidade socioprofissional. No mesmo sentido, no Documento de Apoio às Metas Curriculares de História e Geografia de Portugal (2013, p.5) faz-se referência às capacidades transversais a desenvolver ao longo do $2^{\circ}$ Ciclo do Ensino Básico, entre as quais, no âmbito da comunicação/transmissão do saber, a utilização de "linguagens e suportes diversos (nomeadamente os suportes de comunicação proporcionados pelas tecnologias de informação) na transmissão e divulgação do conhecimento histórico-geográfico". Destaca-se, ainda, a importância "que deve ser atribuída aos instrumentos e materiais de suporte multimedia, de modo a tirar partido do atual apetrechamento tecnológico das escolas e realizar atividades capazes de concretizar de modo mais efetivo os propósitos de aprendizagem" (p.2).

\section{Flipped classroom}

As Tecnologias de Informação e Comunicação (TICs) delinearam novas tendências educacionais. Todavia, não basta projetar slides - usando a tecnologia como método substituto das abordagens tradicionais -, é essencial renovar as cinco dimensões do modelo de maturidade da sala de aula do futuro, definidas pelo iTec Project: o papel do professor; o papel do aluno; os objetivos de aprendizagem e a avaliação; as ferramentas e os recursos e por fim, a capacidade da escola em aprovar a inovação. De modo a que os alunos desempenhassem um papel mais ativo no desenvolvimento das suas competências e no aprofundamento dos seus conhecimentos em História e Geografia de Portugal adotou-se a metodologia flipped classroom. Com raízes no método socrático de ensino, popularizou-se internacionalmente pela voz de autores como Eric Mazur; Lage, Platt e Treglia; Salman Khan; Bergmann e Sams; Bishop e Verleger; Jason Bretzmann e Ariane Dumont, e, atualmente, a flipped classroom é implementada em distintas coordenadas geográficas, em diversas áreas do saber e com alunos de diferentes grupos etários.

Nos inícios dos anos 1990, o professor Eric Mazur relatou que solicitava aos seus alunos, como trabalho de casa, a leitura do livro de texto ou dos apontamentos por si fornecidos, propondo que as suas aulas se alicerçassem na identificação de dificuldades, na apresentação de outros exemplos, no aprofundamento de conhecimentos e na construção de uma relação de confiança mútua. 
Influenciados pelo artigo, publicado em 2000 no Journal of Economic Education, intitulado "Inverting the Classroom: A Gateway to Creating an Inclusive Learning Environment”, de autoria de Lage, Platt e Treglia, em que se relata a experiência pioneira de dois professores de Microeconomia da Universidade de Miami durante o outono de 1996, Jonathan Bergmann e Aaron Sams, docentes de Química no Woodland Park High School em 2007, discutiram a pertinência e adequabilidade da flipped classroom para minimizar os efeitos da ausência dos alunos das atividades letivas. Aperceberam-se de que a participação em atividades extracurriculares e o facto de uma parte desses alunos residir em zonas longínquas da escola influenciavam a sua assiduidade. Nesse artigo descrevia-se uma ferramenta de software que permitia a gravação de uma apresentação PowerPoint, a inclusão de voz e de anotações, transformando-se depois num ficheiro de vídeo - a videoaula. Assim, a dupla de professores constatou que não necessitava de despender um considerável número de horas não letivas a explicar os conteúdos aos discentes abstencionistas, uma vez que bastava remetê-los para os vídeos publicados online. Não só esses alunos viam os vídeos, também alguns que tinham assistido reviam os conteúdos e outros recorriam aos vídeos como estratégia de revisão para as provas de avaliação. Inesperadamente, os seus vídeos começaram a ser utilizados por docentes e discentes de todo o mundo (Bergmann; Sams, 2012).

O exemplo mais conhecido da produção de vídeos explicativos é o de Salman Khan que, em 2004, queria ajudar sua prima Nadia, de 13 anos de idade, que vivia em New Orleans, a estudar matemática. Salman concordou em ensiná-la por telefone e, para ilustrar os conceitos matemáticos que estavam a ser descritos, a dupla entrava no Yahoo Messenger. O explicador usava a janela de desenho do programa para escrever equações enquanto ela assistia a distância. Quando não podiam realizar a chamada, Khan gravava a explicação em vídeo, na qual explicava a matéria utilizando o Microsoft Paint. Um dia, sua sobrinha disse-lhe que preferia os vídeos às chamadas telefónicas porque dessa forma poderia rever o vídeo ou passar à frente as partes que já conhecia. Segundo Salman Khan, "Ela basicamente disse: "Eu gosto mais de ti em vídeo do que pessoalmente!” (Thompson, 2011, s.p.). Esses vídeos tornaram-se tão significativos, que Khan começou a catalogá-los e desenvolveu a Khan Academy, inspirando alunos, professores e pais de todo o mundo. Aliada à 
popularidade da Khan Academy, a flipped classroom conquistou destaque e credibilidade na comunidade educativa (Gerstein, 2012).

A American Society for Engineering Education (ASEE), em 2013, publicou um artigo intitulado "The Flipped classroom: A Survey of the Research", em que se apresentam os resultados de uma pesquisa prévia e contínua sobre a flipped classroom, identificando a tipologia de atividades desenvolvidas dentro e fora da sala de aula, os parâmetros de avaliação do estudo e as características metodológicas. Os resultados desse estudo mostram que as percepções dos estudantes sobre essa metodologia são globalmente positivas (Bishop; Verleger, 2013).

Jason Bretzmann (2013), reconhecido professor de AP Government and Politics na escola Muskego-Norway, desde meados da década de 1990 incorpora ferramentas tecnológicas em sua prática pedagógica. Após ter ouvido o comentário "O PowerPoint é uma terrível forma de aprender!", proferido no final do ano letivo por uma aluna do último ano do ensino secundário, decidiu inverter as suas aulas. Os seus alunos, ao início, reagiam com ceticismo, seguindo-se o alvoroço de participarem ativamente na construção do seu conhecimento mediante trabalho colaborativo. Bretzmann concluiu que os seus estudantes entravam na sala de aula preparados e com os conhecimentos necessários para aplicar, avaliar e criar algo novo.

Dumont (2016) defende que o modo mais simples de definir a flipped classroom é por sua comparação com a abordagem tradicional, em que geralmente a exposição dos conteúdos é realizada pela voz do professor, dentro da sala de aula, num determinado horário, e a componente mais difícil de gerir surge quando os alunos estão fora da sala de aula, sem a supervisão e o feedback do professor. Ora, é exatamente isso que se altera na flipped classroom. Essa abordagem poder-se-á dividir em três etapas. A primeira etapa, a exposição dos conteúdos, acontece no tempo livre dos alunos quando se preparam para a aula: assistindo a um vídeo ou organizando as informações das videoaulas num esquema-síntese. Durante a aula, os alunos desenvolvem os principais conceitos ou ideias, interagem com os seus pares e com o professor. O ciclo completa-se depois da aula, quando os alunos fazem uso do feedback emitido para continuar as suas aprendizagens, revendo os conceitos que consideraram mais difíceis, confusos ou interessantes. 


\section{Metodologia}

Os participantes constituíam uma turma de 22 alunos do $5^{\circ}$ ano de escolaridade, com idades compreendidas entre os 10 e os 13 anos. A discrepância de idades justifica-se pela existência de seis alunos que ficaram retidos pelo menos uma vez ao longo do seu percurso académico: três dos quais encontravam-se a repetir o $5^{\circ}$ ano de escolaridade.

Definida a problemática em estudo, seguiu-se a sua fundamentação em referências da literatura e a planificação da intervenção pedagógica em História e Geografia de Portugal que percorreu as seguintes etapas. Primeiramente, distinguiu-se a abordagem tradicional da abordagem flipped classroom, definiram-se os papéis do professor e do aluno, os objetivos de aprendizagem, a avaliação, as ferramentas e os recursos em cada abordagem. Como tal, na planificação das aulas tradicionais encetaram-se esforços no sentido da criação de um ambiente de aprendizagem dinâmico e estimulante, desenvolvendo atividades como a exploração de documentos projetados (mapas, painéis, crónicas de viagem, reconstituições); a análise de conceitos-chave; a elaboração de sínteses; a construção de frisos cronológicos e a visualização de vídeos em contexto de sala de aula. Apenas no final da $3^{\text {a }}$ aula se justificou a realização de atividades de consolidação de conhecimentos como trabalhos de casa.

No que concerne à recolha de dados, no presente estudo privilegiou-se uma investigação de natureza qualitativa. Implementaram-se dois questionários: um no início e outro no final da intervenção, pela sua utilidade na apreciação de efeitos. Para apoiar a observação participante, optou-se pela redação de um texto pessoal no diário de bordo, ao final de cada sessão, no qual se descreve a perceção que a investigadora "tem dos acontecimentos em função do seu quadro de referência teórico, das suas dúvidas e do desenrolar da sua investigação" (Evertson; Green, 1986, referidos por Lessard-Hébert et al., 2005, p.154). A observação participante possibilita o acesso às ações, opiniões e perspetivas dos observados. A análise documental examinou os documentos produzidos por todos os alunos da turma de modo a expor o ambiente de aprendizagem ao longo da intervenção. Adotaram-se estratégias tendo em vista a confirmação da veracidade dos dados recolhidos, a garantia dos resultados obtidos e a isenção das conclusões extraídas. Primou-se pela triangulação, que se refere às combinações metodológicas, descritas anteriormente, de modo a 
comparar os dados obtidos e comprová-los; pela observação persistente, que permite interpretações de diferentes ângulos combinadas com um processo de análise constante e pela revisão pelos pares, sob forma de conversas com o professor orientador e outros investigadores, o que possibilitou diferentes perspetivas sobre a investigação. Na análise dos dados optou-se por uma estratégia composta por duas componentes: a representação por particularmente evidente e o tratamento estatístico, para uma mais fácil e rápida identificação da tendência geral dos dados.

\section{Resultados E Discuss Ão}

\section{Questionário inicial}

As respostas ao primeiro questionário, que tinha como objetivo conhecer a relação dos alunos com as Tecnologias da Comunicação e Informação (TICs), foram bastante esclarecedoras, mostrando evidências da familiaridade dos alunos com as novas tecnologias. A maioria (13 alunos) declara que contacta com o computador ou tablet há mais de 2 anos, e 11 alunos asseguram que esse contacto é diário. Usam-no(s) não só explicitamente para o lazer (jogar - 19 alunos; ouvir música - 15 alunos; interação social - 6 alunos) mas também para atividades académicas (elaborar trabalhos escolares - 16 alunos; explorar CD educativos - 7 alunos) e para outras atividades que intersetam os dois âmbitos (pesquisa na internet - 14 alunos; ver vídeos online - 12 alunos; editar imagens e vídeos - 9 alunos). Desses alunos, 16 usam o computador para fins escolares porque gostam; 6 escolhem-no porque é mais prático, e nenhum aluno o faz porque é obrigado. No que diz respeito à relação do grupo com a internet: 3 alunos revelam que nunca a usaram, 5 afirmam que a utilizam há pelo menos 6 meses, e 14 alunos usam a internet há mais de 2 anos, 8 dos quais dizem utilizá-la há mais de 5 anos, podendo esse resultado ser entendido pela familiaridade dos estudantes com a rede. Apenas 6 alunos não têm acesso à internet em casa. Os 22 alunos afirmaram que ao longo do ano letivo 2014/15 visualizaram vídeos dentro da sala de aula nas aulas de Ciências Naturais, Inglês, Educação Visual, Educação Tecnológica, Educação Física e Educação Moral Religiosa Católica. Relativamente às atividades que costumam realizar após a visualização do vídeo a opinião da turma não é unânime. Os alunos 
revelam que nunca lhes foi proposta a visualização de um vídeo como trabalho de casa. No entanto, 12 alunos manifestam que já procuraram vídeos para esclarecer as suas dúvidas.

\section{Abordagem tradicional}

Passa-se agora à descrição da abordagem tradicional dos conteúdos. $\mathrm{Na}$ primeira aula, os alunos demonstraram ter bons conhecimentos sobre os desafios, as motivações e as condições para o pioneirismo português na expansão. Para além disso, uma minoria extrapolou as informações relacionando-as com a atualidade: "Por que é que Portugal agora não tem aqueles territórios?”; “As caravelas andavam a gasolina?”. Os alunos demonstraram a intenção de selecionar informação, distinguindo o essencial do acessório, ao questionarem se poderiam estudar para a Ficha de Avaliação a partir das sínteses produzidas. Durante a segunda sessão, os alunos mostraram-se bastante participativos, graças à existência de atividades que intercalavam a exposição dos conteúdos, contribuindo ainda mais para o envolvimento do grupo. No entanto, transpareceu um dilema bastante frequente nas salas de aulas: a luta contra o relógio. Adotou-se o "Baú das Mensagens", onde os alunos poderiam colocar questões, anonimamente ou não, sobre assuntos relacionados com os conteúdos, todavia não abordados no Currículo. Mais tarde, verificou-se que o Baú das Mensagens promoveu oportunidades para o esclarecimento de dúvidas, indo ao encontro dos seus gostos. Com isso, os alunos sentiam-se capacitados para aprender sobre temas do seu interesse e mais confortáveis para tomar os lemes da sua aprendizagem. Considera-se que na última aula da abordagem tradicional os alunos deveriam desempenhar um papel mais ativo na construção da sua aprendizagem. A turma demonstrou bons conhecimentos sobre as grandes viagens transatlânticas dos povos peninsulares, fruto das suas vivências do $1^{\circ}$ Ciclo do Ensino Básico e das adquiridas fora da sala de aula, pelos media.

Após o período de observação e a implementação dessas três sessões, pode-se categorizar genericamente a turma em dois grandes grupos: alunos pouco participativos e acostumados a ouvir e alunos participativos, estando todos conformados no desempenho do seu papel. No início do período de implementação propôs-se, mesmo seguindo a metodologia tradicional, torná-los mais dinâmicos e conscientes da sua aprendizagem. Constatou-se que alguns dos alunos do primeiro grupo tornaram-se participativos e verificou-se 
uma melhoria significativa na organização dos seus cadernos diários. O segundo grupo de alunos demonstrava o seu gosto pela História e Geografia de Portugal, no entanto, por vezes aparentavam estar entediados. Nesse grupo destacou-se um aluno, habituado a liderar a turma, que gostava de dar a conhecer a sua opinião e, com isso, anulava possíveis participações dos colegas. Nas duas primeiras aulas mostrou-se muito agradado, comentando que essas aulas eram mais "interativas". Na última sessão, assumiu uma atitude oposta, mostrando-se desinteressado o que, para além de ser um modo de chamar atenção, leva a crer que esta é a forma mais expansiva de mostrar o seu desagrado com o atual modelo.

\section{Abordagem flipped classroom}

$\mathrm{Na}$ transição explicaram-se as características da flipped classroom. Os alunos mostraram-se curiosos com as atividades a serem, então, realizadas em tempo letivo, ficaram bastante entusiasmados com os desafios, a exploração de documentos, em trabalho a pares ou em grupo. Alguns apresentaram-se reticentes à ideia de debate. Conceberam-se videoaulas, utilizando ferramentas como o PowerPoint e o Camtasia, de acordo com as indicações para faixa etária (10 aos 15 anos de idade) com duração entre os 7 e os 10 minutos (Seigel, 2013), em que se explicam e exemplificam os conteúdos. Sua distribuição realizou-se online no YouTube e em DVD, uma vez que as turmas do $5^{\circ}$ ano ainda não estavam integradas na fase embrionária da plataforma e-learning e seis alunos não tinham acesso à internet em casa. Apenas uma minoria possuía um endereço de correio eletrónico. Por conseguinte, foi por meio de um bilhete, em papel, com a hiperligação, o Código QR e o título da videoaula, que os alunos acediam ao material multimedia.

Solicitou-se aos alunos a visualização das videoaulas antes do início do tempo em sala de aula e, como forma de verificação da realização da atividade e de identificação de dúvidas, os alunos deveriam, no seu caderno diário, responder a um desafio colocado na videoaula. Este seria corrigido, na aula, pelo esclarecimento entre pares, proporcionando aos alunos peritos no domínio dos conteúdos a oportunidade de esclarecerem as dúvidas dos seus colegas. Destinou-se o tempo letivo para o aprofundamento dos conteúdos e o desenvolvimento de competências pela resolução de problemas e por trabalho colaborativo, esclarecimento entre pares e discussão. Findados os primeiros 15 
minutos da primeira intervenção flipped classroom, a turma já havia: registado o sumário; visualizado a videoaula - atividade que não estava prevista; verificado o esquema-síntese, confrontando as suas ideias, esclarecendo as suas dúvidas e construindo o seu pensamento histórico. Poder-se-ia imaginar um cenário em que todos os alunos tivessem visualizado a videoaula. Numa abordagem tradicional, o alcance desses mesmos objetivos despenderia pelo menos um tempo letivo (45 minutos), mas nesta aula restavam ainda mais 75 minutos para trabalhar com a turma, em sala de aula, a desenvolver mestrias. Destaca-se como ponto forte a dinâmica do grande grupo, ou seja, todos os alunos estão ocupados, a resolver, a pensar e a colaborar. Não há alunos passivos, nem tempos mortos, os alunos têm a oportunidade de elucidar as suas dúvidas com os seus pares ou com a professora-investigadora. O tempo letivo é verdadeiramente aproveitado, uma vez que todos identificam as suas dúvidas e esclarecem-nas. As relações aluno-professora e vice-versa saíram reforçadas pois, ao circular pela sala de aula, a docente conversa com cada conjunto de alunos, ajudando-os a solucionar os seus dilemas. Foi clara a diferença de ritmos entre os elementos da turma, porém não se assumiu como um fator desestabilizador. Notou-se que alguns alunos evidenciam marcas da metodologia tradicional (“A professora não ajuda o nosso grupo!”). Em futuras intervenções, deve-se incitar o debate, a pesquisa e o esclarecimento de dúvidas dentro do próprio grupo, reforçando que todos os elementos deverão ser mestres no domínio dos assuntos, assim como motivar os alunos para a visualização da próxima videoaula, evitando os níveis de abstenção. Na segunda intervenção flipped classroom, o papel docente assumiu-se como facilitador das aprendizagens mediante debate, resolução de problemas e dissipação das dúvidas. Os alunos, nessa sessão, mostraram agrado com a utilização de videoaulas, afirmando: "Gosto que a professora faça vídeos porque assim posso pará-los, voltar atrás e ver de novo"; "Vou ver todas as videoaulas ao estudar para o teste!". A intervenção seguinte pautou-se por um ambiente de aprendizagem dinâmico, em que todos os alunos se envolveram e motivaram para a sua aprendizagem. Os alunos confrontaram-se com uma nova dinâmica, o trabalho a pares, e todas as díades partilharam ideias no sentido da resolução da questão-problema. Assistiu-se a uma rentabilização do tempo letivo e a uma diversidade de atividades propostas. Na sala dos computadores, espaço que poderá assustar alguns professores, todos os alunos, sem exceção, participaram ativamente na 
descodificação do seu documento iconográfico. Nesse sentido, verifica-se que não só se deve incluir o uso das TICs nas diversas áreas do saber, como também se deve impulsionar o contacto com documentos iconográficos no ensino da História e Geografia de Portugal. Ao se prepararem para a última sessão flipped classroom, os alunos não tiveram de visualizar uma videoaula, pois as noções básicas haviam sido transmitidas na anterior. Essa aula foi reservada para a apresentação de trabalhos no suporte PowerPoint. Ao apresentarem e discutirem a sua análise dos documentos iconográficos, os alunos tiveram a oportunidade de mostrar o domínio dos conteúdos.

Na planificação das aulas flipped classroom selecionaram-se os conteúdos a serem explicados nas videoaulas e as características das propostas a desenvolver na sala de aula. É fora desta, nas videoaulas, que os alunos contactam primeiramente os conteúdos, desenvolvendo habilidades de pensamento de ordem inferior como lembrar e entender. A preparação das videoaulas exige uma seleção cuidada de imagens, conceitos escritos e texto narrado, criando um ambiente o mais semelhante com o da explicação em sala de aula. Após a elaboração do suporte visual mediante apresentação PowerPoint, tendo em conta essas preocupações, procede-se à narração e captura de tela através do software Camtasia. Por fim, editavam-se e disponibilizavam-se os conteúdos multimedia. A existência de um desafio no final da videoaula, que se afigurava como um esquema ou texto incompleto a ser respondido no caderno diário, contribuiu para o desenvolvimento do segundo nível da Taxonomia Revista de Bloom - entender. Esse desafio assume-se também como ferramenta de aferição da visualização das videoaulas, e sua correção dava continuidade à dinâmica iniciada fora da sala. A resposta às questões-problema vinha aferir o domínio sobre os conteúdos iniciado fora da sala de aula. De modo genérico, todas as aulas flipped classroom marcaram-se por uma atividade estrutural que poderia pautar-se por: resolução de problemas, análise de documentos, prparação para o debate, participação ativa neste, desenvolvendo habilidades de pensamento de ordem superior como analisar e avaliar, descodificação de documentos iconográficos e apresentação destes. Nessa abordagem, estimulam-se a demonstração de competências e a prossecução de objetivos de aprendizagem mediante trabalho colaborativo e esclarecimento entre pares, discutindo os seus resultados com os colegas. 


\section{Fichas de avaliação}

Considerou-se pertinente analisar a prestação dos alunos nas Fichas de Avaliação, instrumento usado na mediação da aprendizagem, a dois níveis: externamente, comparando os resultados obtidos na Ficha de Avaliação referente ao período de implementação com as realizadas até então pelo professor cooperante; e a nível interno, confrontando a sua primeira parte, ministrada sob a metodologia tradicional com a segunda parte, lecionada de acordo com a flipped classroom. A 5a Ficha de Avaliação elaborou-se de acordo com a estrutura já conhecida dos alunos. Na parte I, reservou-se 10\% da Ficha de Avaliação para os conteúdos lecionados pelo professor cooperante ainda não submetidos a essa ferramenta de avaliação; para os restantes $90 \%$ dos conteúdos, atribuiu-se metade da cotação aos conteúdos ensinados segundo a abordagem tradicional (parte II) e a restante cotação aos conteúdos lecionados mediante flipped classroom (parte III). Os resultados dessa Ficha de Avaliação apresentam não só uma diminuição do número de negativas para duas (Gráfico 1) como também um aumento da nota mínima para 33\% e da nota média para 69,9\% (Gráfico 2). Assim, é possível afirmar que os conceitos foram assimilados pelos alunos. Nessa $5^{\text {a }}$ Ficha de Avaliação (Gráfico 3), além das referidas duas classificações negativas (33\% e 43\%); dez alunos atingiram o nível de Satisfaz, cinco alunos atingiram o nível Satisfaz Bastante, atingindo valores entre os $72 \%$ e os 84\%, e igual número de alunos obteve o nível de Excelente. Constata-se que, na parte I, três alunos alcançaram a percentagem máxima (10\%) e oito alunos obtiveram menos da metade desta. Na parte II, alusiva à abordagem entendida como mais tradicional, os alunos 14, 15 e 20 conseguiram o desempenho máximo. Na parte III, referente à metodologia flipped classroom, os alunos 10 e 20 demonstraram domínio sobre todos os conteúdos. Ao se comparar a prestação dos alunos nas partes II e III, verifica-se que a maioria, 18 alunos, teve melhor desempenho na parte III em comparação com a parte II; por oposição, quatro alunos obtiveram melhor desempenho nos conteúdos da parte II do que na parte III (aluno 7, aluno 14, aluno 15 e aluno 17). O aluno 20 obteve a pontuação máxima em ambas as partes. Na parte II, seis alunos ficaram abaixo dos $22,5 \%$, marca da metade da cotação, mas na parte III, apenas um aluno não conseguiu ultrapassar esse limite (aluno 18). 


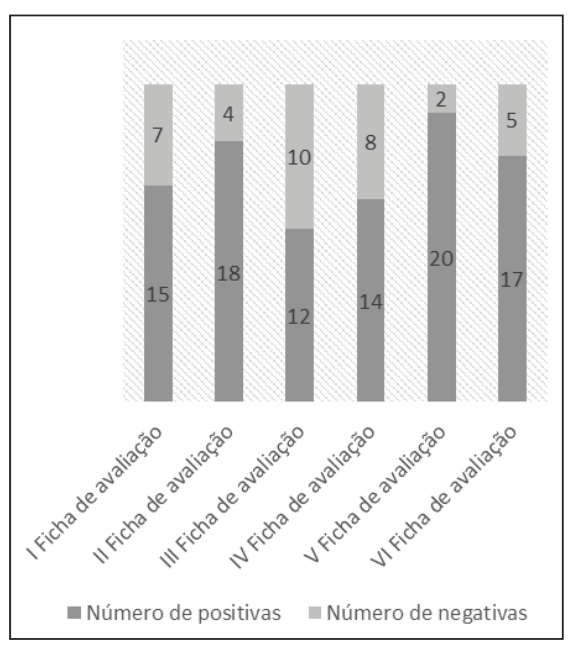

Gráfico 1 - Notas mínimas, médias e máximas nas Fichas de Avaliação

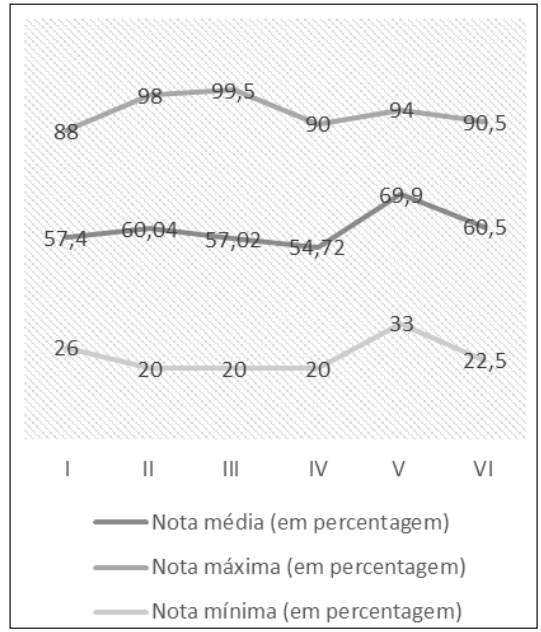

Gráfico 2 - Relação de positivas e negativas nas Fichas de Avaliação

\section{Questionário pós-implementação}

De modo a conhecer a perceção dos alunos sobre a intervenção pedagógica, no questionário pós-implementação inquiriu-se sobre metodologia tradicional e, depois, sobre a flipped classroom. No que se refere à metodologia tradicional, nove alunos afirmam que faziam questões menos de uma vez por semana, dos quais três nunca questionavam, nove faziam-no uma vez por aula, e quatro alunos revelaram fazer perguntas diversas vezes por aula. A maioria dos alunos (14) revelou que se esforçava ao máximo na realização das atividades do manual ou guião de estudo como trabalho de casa, quatro alunos afirmaram que apenas realizavam algumas dessas atividades, e o mesmo número de alunos assumiu que não se esforça muito nessas propostas. Apenas dois alunos concordaram que, durante as aulas expositivas, o ritmo foi muito lento. Em oposição, um aluno revelou que o ritmo dessas mesmas aulas foi muito acelerado, de modo que não conseguiu tomar notas. Durante as aulas da abordagem tradicional, 12 alunos concordaram e dez discordaram em que o ritmo foi adequado e conseguiram tomar notas. Os alunos discordaram ou discordaram totalmente que se tenham distraído com os seus colegas, havendo cinco alunos que concordaram em ter sentido dificuldades em 
ouvir a professora e tomar notas em simultâneo. Acresce a constatação, já anteriormente referida, de que nenhum aluno, nos seus cadernos diários, registou apontamentos, por sua livre iniciativa, durante a abordagem tradicional. Relativamente às atividades preferidas destacam-se a interação com a professora e o registo de sínteses - como primeiras preferências de oito alunos. Seguem-se propostas de aprendizagem ativa como a construção de friso cronológico (três alunos) e a análise de documentos (três alunos). Evidenciam-se como atividades menos preferidas: a realização do trabalho de casa (sete alunos), o registo de sínteses (seis alunos) e a realização do guião de trabalho (seis alunos). Sendo a última questão, referente à metodologia tradicional, aberta, opta-se por preservar as palavras originais dos alunos na Tabela 1. Assim, 15 alunos referiram que não alteravam nada nas primeiras aulas, sete alunos mudavam as primeiras aulas, seis dos quais incluíam elementos que vieram a experimentar na segunda metade da intervenção pedagógica.

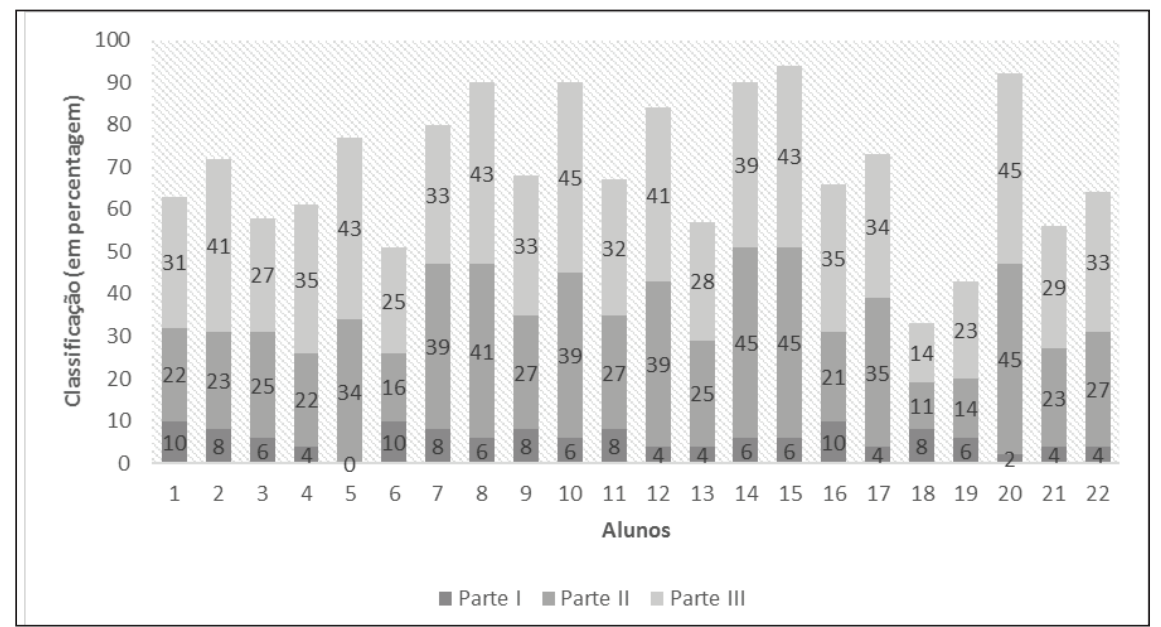

Gráfico 3 - Distribuição das classificações da 5a Ficha de Avaliação 
Tabela 1 - Mudavas alguma coisa nas primeiras aulas de HGP? O quê?

Respostas dadas (transcrição):

Sim, gostava que tivessem mais paiorpoit [sic].

Sim, ver mais videoaulas.

Sim, queria ver videoaulas.

Sim, gostava de ver maís vídeos.

Sim, eu mudava. Gostava que a professora tivesse mandado ver mais vídeos.

Sim, gostava de nas primeiras aulas, ter trabalhado mais em grupo.

Sim, eu queria ver mais videoaulas porque assim podia rever a matéria para o teste.

Não (11 respostas)

Não alterava nada nas primeiras aulas de história e geografia de Portugal

Não, eu acho que as aulas foram boas como foram.

Não, eu gostei das aulas de história porque foi tudo interativo.

Eu não mudava, nem mudo nada.

$\mathrm{Na}$ implementação da metodologia flipped classroom, no que se refere às videoaulas, 16 alunos visualizaram todas as videoaulas, cinco alunos visualizaram duas, e um aluno assistiu apenas a uma das três. No que respeita à sua repetição, 20 alunos afirmaram terem repetido as videoaulas mais de duas vezes, e apenas dois garantem terem-no feito apenas uma vez. Metade da turma declarou que pausava a visualização da videoaula mais de sete vezes. Durante a visualização, 16 alunos asseguram ter realizado apontamentos. Após a visualização da videoaula, 13 alunos sentiam-se extremamente confiantes com os conteúdos, enquanto os restantes nove estavam pouco confiantes, precisando de mais ajuda. Os alunos discordaram ou discordaram completamente de não terem completado o(s) desafio(s) da(s) videoaula(s) porque não conseguiram realizar apontamentos. Consideram ainda que a(s) videoaula(s) os preparava(m) para o desafio. Oito alunos concordaram e um aluno concordou plenamente em que não completaram o(s) desafio(s) da videoaula porque compreenderam os exemplos e não sentiram necessidade de realizar o exercício. Vinte alunos afirmaram que se esforçavam ao máximo no trabalho de casa - visualização da videoaula e resolução do desafio. Apenas um aluno sugeriu uma alteração nas videoaulas: a utilização de excertos de filmes (Tabela 2). 
Tabela 2 - Mudavas alguma coisa nas videoaulas? O quê?

Respostas dadas (transcrição):

Sim, em vez de ter imagens podia ter pedaços de filmes.

Não (15 alunos)

Não porque fiquei com mais conhecimentos.

Não, mudava nada nas videoaulas.

Não mudava nada porque achei as videoaulas muito divertidas.

Não porque as videoaulas estão bem assim.

Não. Eu gostei de todas!

Não porque foram muito divertidas.

Relativamente à utilidade da questão-problema no início da aula, sete alunos afirmaram que era útil a maioria das vezes, os restantes 15 revelaram ser útil sempre. Apenas três alunos não apresentaram opinião acerca do Baú das Mensagens, um outro mostrou-se contrário a essa proposta. Os restantes 18 alunos mostraram o seu apoio e entusiasmo com essa atividade (Tabela 3).

Tabela 3 - Qual a tua opinião sobre o Baú das Mensagens?

Respostas dadas (transcrição):

Muito mau porque se quisesse-mos tirar dúvidas tirava-mos nas aulas.

Sem opinião. (3 respostas)

Boa! (2 respostas)

Muito bem!

Bom porque podia colocar questões em anónimo.

Foi importante porque deu parar esclarecer as minhas dúvidas.

É uma super boa ideia porque retirava as dúvidas de todos os alunos da turma.

Ajuda-nos a perceber melhor a matéria!

Concordo plenamente.

Muito bom, assim conheci algumas curiosidades da História.

Na minha opinião, o Baú das Mensagens é muito importante porque podemos tirar dúvidas. 
É bom porque assim pudemos esclarecer todas as nossas dúvidas.

É muito importante porque posso tirar dúvidas sobre a matéria que estámos a estudar e sobre outras que não estudámos.

Eu achei bem porque assim pudemos tirar as nossas dúvidas.

Achei importante porque assim tirámos as nossas dúvidas.

Na minha opinião, o Baú das Mensagens é bom porque deu para esclarecer as nossas dúvidas mais importantes para os alunos.

Foi bom porque assim tirava-mos dúvidas.

Eu acho que o baú de mensagens foi uma boa ideia para tirar dúvidas que tínhamos nas aulas.

Eu achei bem porque assim podemos tirar as nossas dúvidas.

Dez alunos revelaram que a sua atividade preferida, na segunda metade das aulas de História e Geografia de Portugal, era o trabalho de grupo, seguindo-se o esclarecimento de dúvidas com a professora (três alunos), o esclarecimento de dúvidas com os colegas (três alunos) e a apresentação dos documentos iconográficos (três alunos), a visualização da videoaula (dois alunos) e a resposta à questão-problema (um aluno). A correção do desafio apresenta-se como a atividade menos preferida da turma (seis alunos). A maioria dos alunos (17 alunos) afirmou que gostaria que na próxima aula de História e Geografia de Portugal se adotasse a metodologia flipped classroom, alegando o gosto pela visualização das videoaulas, os seus benefícios na preparação para a Ficha de Avaliação, a correção dos desafios na aula; a facilidade em realizar anotações e em esclarecer dúvidas; a interação com os colegas; o trabalho de grupo; a apresentação dos documentos à turma e a realização de "atividades diferentes das que estava habituado", distinguindo-se das restantes disciplinas. Consideram ainda que compreenderam melhor os conteúdos e estes eram bem explicados. Um aluno referiu que gostava das aulas flipped classroom, "porque fazia-mos [sic] exercícios em grupo e isso dava-nos criatividade”, no sentido em que os alunos tinham mais liberdade para construírem os seus conhecimentos. Os restantes cinco alunos justificam a predileção pela abordagem tradicional pelos conteúdos lecionados na primeira metade da intervenção, o gosto pelas explicações pela voz da professora e a facilidade em esclarecer 
dúvidas. Um aluno, embora escolha as aulas Not flipped classroom explica que não tem uma predileção por uma metodologia específica (Tabela 4).

Tabela 4 - Justificações para a escolha

Respostas dadas (transcrição):

Not flipped classroom, gostei mais das primeiras aulas porque era sobre a chegada de Vasco da Gama a Índia.

Not flipped classroom, porque era mais fácil de perceber a matéria e tirar dúvidas. Gostei muito da forma como a professora explica.

Not flipped classroom, porque via-mos o entusiasmo da professora e eu gostava mais do que ver vídeos. As suas aulas foram muito fixes, porque foram interativas.

Not flipped classroom, porque conseguia-mos tirar as dúvidas na aula com a professora. E também víamos o empenho que a professora fazia para nos esclarecer as dúvidas e nos ensinar a matéria.

Not flipped classroom, gostei de aprender com os poweir points [sic], mas também gostei das videoaulas.

Flipped classroom, porque fizemos trabalhos em grupo.

Flipped classroom, eu gostei de trabalhar em grupo e de descodificar e apresentar o nosso documento à turma em poiorpoint [sic].

Flipped classroom, gostei das videoaulas porque podia tinha mais facilidade em tirar os meus apontamentos.

Flipped classroom, porque fiz atividades diferentes das que estava habituado.

Flipped classroom, porque dialogámos com os outros e era a professora.

Flipped classroom, porque era a professora e sobre tudo retiramos as nossas dúvidas.

Flipped classroom, porque se percebe melhor. Eu com as videoaulas aprendi muito sobre as descobertas e conquistas dos Portugueses. Aprendi coisas novas, com os colegas e com a professora.

Flipped classroom, porque era interessante e diferente das outras disciplinas.

Flipped classroom, porque se percebe melhor. Adorei todas as aulas.

Flipped classroom, porque explicavam bem e aprendi muita cousa. 
continuação

Flipped classroom, o que eu mais gostei foi fazer trabalhos em grupo, ver as videoaulas porque os vídeos deram para perceber melhor matéria.

Flipped classroom, porque gosto de ver vidios [sic].

Flipped classroom, porque gostei das videoaulas e fizemos a correção dos desafios na aula.

Flipped classroom, porque fazia-mos exercícios em grupo e isso dava-nos criatividade. Fiquei a perceber melhor as coisas.

Flipped classroom, porque tinha os vidios [sic] porque era importante para estudar para o teste.

Flipped classroom, porque gostei muito das aulas e das videoaulas e gostei muito da professora.

Flipped classroom, porque o T.P.C. dos vídeos foi muito fixe. Gostei muito.

\section{CONSIDERAÇÕES FINAIS}

Neste trabalho de investigação decidiu-se adotar a flipped classroom por três motivos. Primeiro, objetivava-se uma participação ativa e efetiva dos 22 alunos, entre os 10 e os 13 anos, do $5^{\circ}$ ano de escolaridade no seu processo de aprendizagem e no dos seus pares, assim como uma experiência de aprendizagem enriquecedora e atraente, apoiando o desenvolvimento de competências para o século XXI. Segundo, ambicionava-se motivar os alunos para o gosto pela disciplina de História e Geografia de Portugal. Por fim, a discussão em torno da flipped classroom cita estudos desenvolvidos fora do contexto educativo português, principalmente nas ciências exatas, com alunos do ensino secundário e superior pelo que se considerou pertinente investigar a viabilidade dessa metodologia. A intervenção didática, em que a primeira metade das aulas era norteada pela abordagem entendida como tradicional e a segunda metade das aulas orientadas pela flipped classroom, foi delineada em conformidade com os objetivos do estudo, tendo em conta o Programa e as Metas Curriculares de História e Geografia de Portugal do $2^{\circ}$ Ciclo do Ensino Básico e as características do contexto educativo - predominantemente rural. Tendo em conta esses pressupostos, consultaram-se algumas referências bibliográficas consideradas pertinentes para fundamentar as opções tomadas. 
A implementação da flipped classroom é exequível no processo de ensino e aprendizagem da História e Geografia de Portugal de uma turma do $5^{\circ}$ ano de escolaridade e os alunos tornaram-se mais responsáveis e conscientes do seu próprio processo de aprendizagem. Pressentiram-se dificuldades no acesso às videoaulas uma vez que, no horário da turma, as aulas da disciplina eram em dias consecutivos, sendo o primeiro dia repleto de atividades letivas. Seis alunos não visualizaram todas as videoaulas, realidade pouco diferente do boicote que alguns fazem à exposição dos conteúdos na sala de aula, na metodologia tradicional, tal como afirma Plunkett (2014). As respostas à última questão do questionário final são bastante esclarecedoras: 17 alunos afirmam que gostariam que a próxima aula de História e Geografia de Portugal seguisse a metodologia flipped classroom. Essa perceção é fundamentada na utilidade das videoaulas para a sua aprendizagem, considerando-as (1) importantes para a revisão dos conteúdos para a Ficha de Avaliação, (2) facilitadoras no registo dos apontamentos e (3) condescendentes de atividades em trabalho colaborativo e esclarecimento entre pares, na sala de aula. A utilização de videoaulas favorece os alunos mais distraídos e menos motivados ao possibilitar a revisão dos conteúdos ao seu ritmo e quando estão predispostos e disponíveis. $\mathrm{Na}$ metodologia flipped classroom, alguns alunos quando definem o seu próprio ritmo, demoram mais tempo a dominar determinado conteúdo, e uma vez ultrapassadas as dificuldades tomam facilmente a dianteira. Ao inverter a lógica da sala de aula, aumenta o envolvimento dos alunos nas atividades do grupo e alternam-se as hierarquias dentro do grande grupo (Bergmann; Sams, 2012; Plunkett, 2014). A flipped classroom desperta a responsabilização e consciencialização do aluno pela sua aprendizagem, o que se confirma pelas sínteses espontâneas das videoaulas realizadas por alguns alunos e pela aprendizagem dos seus colegas, com o trabalho colaborativo e o esclarecimento de dúvidas entre os alunos. Mais se infere que o contexto escolar estudado oferece condições de trabalho suficientes para a produção do material multimedia, exigindo ao docente noções elementares no âmbito do domínio das Novas Tecnologias. O tempo despendido na planificação, gravação e edição das videoaulas foi largamente compensado pela reação dos alunos que se tornaram mais empenhados na sua aprendizagem. No $2^{\circ}$ Ciclo do Ensino Básico, em História e Geografia de Portugal, os alunos estão a enriquecer o seu vocabulário sobre os aspetos sociais, e com as videoaulas podem, na comodidade do seu lar, pausar 
e repetir as explicações da sua professora, sem se sentirem constrangidos. Alterou-se uma experiência desumanizada: 22 alunos, sentados, a olhar na mesma direção, proibidos de interagir com os colegas, a explorarem os níveis de pensamento mais baixos da Taxonomia de Bloom (lembrar e entender) por um ambiente de aprendizagem ativa em que os alunos, organizados em pequenos grupos, aplicam, analisam, avaliam e criam. A metodologia flipped classroom corrobora as palavras de Moniot (1993, referido por Félix et al., 1996, p.32), o papel do professor de História não é um modo de passar a vida a conhecer a História com os alunos, mas sim passar a sua vida a conhecer os alunos para os fazer realmente partilhar os saberes que são ao mesmo tempo abundantes e significativos. O professor proporciona experiências práticas sobre o que está previsto aprenderem, privilegiando uma aprendizagem individualizada. Este estudo possibilitou não só abordar a História e Geografia de Portugal de modo inovador, otimizando o recurso mais valioso para os intervenientes educativos - o tempo -, como também dar resposta a algumas exigências que se colocam aos docentes: o conhecimento das necessidades de cada aluno em turmas cada vez maiores.

\section{REFERÊNCIAS}

BERGMANN, Jonathan; SAMS, Aaron. Flip your Classroom: Reach Every Student in Every Class Every Day. International Society for Technology in Education, 2012.

BINKLEY, Marilyn; ERSTAD, Ola; HERMAN, Joan; RAIZEN, Senta; RIPLEY, Martin; RUMBLE, Mike. Defining 21st century skills. In: GRIFFIN, Patrick; MCGAW, Barry; CARE, Esther (Eds.) Assessment and Teaching of 21st Century Skills. Springer, 2012. p.17-66.

BISHOP, Jacob; VERLEGER, Matthew. The Flipped Classroom: A Survey of the Research. In: ASEE ANNUAL CONFERENCE \& EXPOSITION, 120. Washington, DC: American Society for Engineering Education, 2013.

BRETZMANN, Jason. Flipping 2.0. New Berlin: Bretzmann Group, 2013.

DEMSKI, Jennifer. 6 Expert Tips for Flipping the Classroom. 2013. Disponível em: https://campustechnology.com/articles/2013/01/23/6-expert-tips-for-flipping-the-classroom.aspx; Acesso em: 24 set. 2016.

DUMONT, Ariane. But what exactly is a flipped classroom? 2016. Disponível em: www.youtube.com/watch?v=vDM6dajYcO4; Acesso em: 25 set. 2016. 
FÉLIX, Noémia; ROLDÃO, Maria do Céu. Dimensões formativas de disciplinas do ensino básico: História. Lisboa: Instituto de Inovação Nacional, 1996.

GERSTEIN, Jackie. The Flipped Classroom: The Full Picture. Based on an Experiential Model of Learning. 2012. Disponível em: https://usergeneratededucation.wordpress.com/2011/06/13/the-flipped-classroom-model-a-full-picture/.

ITEC PROJECT. Future Classroom Lab. European Comission. s.d. Disponível em: http://fcl.eun.org/pt_PT/tool2p1; Acesso em: 2 maio 2016.

LESSARD-HÉBERT, Michelle; GOYETTE, Gabriel; BOUTIN, Gérald. Investigação qualitativa: fundamentos e práticas. ${ }^{\circ}$. Lisboa: Instituto Piaget, 2005.

MAZUR, Eric. Peer Instruction: A User's Manual. Upper Saddle River, NJ: Prentice Hall, 1997.

MELO, Maria do Céu. Supervisão do Ensino da Histórica: Natureza e Objectivos. In: BARCA, Isabel (Org.) Para uma Educação Histórica de Qualidade. Braga: Actas das IV jornadas internacionais de educação histórica, 2004. p.87-100.

OECD. Skills Outlook 2015: Youth, Skills and employability. 2015. Disponível em: https://www.oecd.org/edu/oecd-skills-outlook-2015-9789264234178-en.htm.

PLUNKETT, K. The Flipped Classroom - A Teacher's Complete Guide: Theory, Implementation and Advice. New York: JIBB Publishing, 2014.

SEIGEL, Marc. Science. In: BRETZMANN, Jason. Flipping 2.0. New Berlin: Bretzmann Group, 2013. p.138-152.

Artigo recebido em 4 de outubro de 2016. Aprovado em 9 de fevereiro de 2017. 